Article

\title{
Optimum Receiver-Side Tuning Capacitance for Capacitive Wireless Power Transfer
}

\author{
Sungryul Huh ${ }^{1}$ and Dukju Ahn ${ }^{2, *}$ \\ 1 The Cho Chun Shik Graduate School for Green Transportation, Korea Advanced Institute of Science and \\ Technology, Daejeon 34141, Korea; tjdfuf2397@kaist.ac.kr \\ 2 Dept. of Electrical Engineering, Incheon National University, Incheon 22012, Korea \\ * Correspondence: adjj22@gmail.com; Tel.: +82-32-835-8767
}

Received: 12 November 2019; Accepted: 9 December 2019; Published: 13 December 2019

check for updates

\begin{abstract}
This paper reveals the optimum capacitance value of a receiver-side inductor-capacitor (LC) network to achieve the highest efficiency in a capacitive power-transfer system. These findings break the usual convention of a capacitance value having to be chosen such that complete LC resonance happens at the operating frequency. Rather, our findings in this paper indicate that the capacitance value should be smaller than the value that forms the exact $\mathrm{LC}$ resonance. These analytical derivations showed that as the ratio of inductor impedance divided by plate impedance increased, the optimum $R x$ capacitance decreased. This optimum capacitance maximized the $T X$-to- $R X$ transfer efficiency of a given set of system conditions, such as matching inductors and coupling plates.
\end{abstract}

Keywords: wireless power transfer; capacitive power transfer; parallel-plate contactless power

\section{Introduction}

Capacitive wireless power-transfer systems wirelessly transmit electrical energy without the use of actual wire coils. Instead, thin metallic plates form a capacitor through which current can flow. Such a system has previously been investigated for biomedical applications [1], electric vehicles [2-5], mobile devices [6], and constant-current applications [7]. Although a variety of circuit topologies are available for capacitive power system [1-8], an inductor-capacitor (LC) section in a receiver (RX) is the simplest topology for systems with small coupling capacitances [2,3]. Additional matching inductors, such as those in [5], require a large inductance value $(\sim 240 \mu \mathrm{H})$, which is too bulky. Parasitic capacitances due to nearby metals can also be merged with a parallel tuning capacitor [2] to form another type of LC section.

Although much work has been done on the LC matching network design, only a few works have focused on efficiency maximization, which is an important key requirement in an effective wireless power-transfer system. Reference [3] proposes operating near the resonance frequency of an inductor and capacitor, either for constant current or constant voltage operation. Their operating frequency would slightly deviate from the self-resonant frequency of an LC matching network for constant voltage or current operation, where the amount of deviation is determined by the strength of the capacitive coupling. At weak coupling, the operating frequency would approach the LC resonant frequency.

While the LC matching design of [3] successfully achieves either constant voltage or current operation, this design does not focus on efficiency maximization. Reference [9] analyzes the effect of matching detuning and proposes a design method to operate over a wide frequency bandwidth. Although this design successfully operated over this wider frequency range via inverter soft-switching, the optimum matching capacitance for maximum efficiency has not yet been discussed.

Reference [8] proposed a resonance-matching network to improve the power factor. This is equivalent to enhancing the real part of $Z_{R X}$, as seen in Figure 1. The large resistive impedance of the receiver 
increased the power factor here because the $\mathrm{CP}$ impedances were highly imaginary. A matching network design [10] also aimed toward power-factor maximization. Unfortunately, as will be discussed later in this paper, power-factor maximization does not necessarily maximize efficiency. Hence, any design method that focused on achieving maximum efficiency would be different from the methods in $[8,10]$.

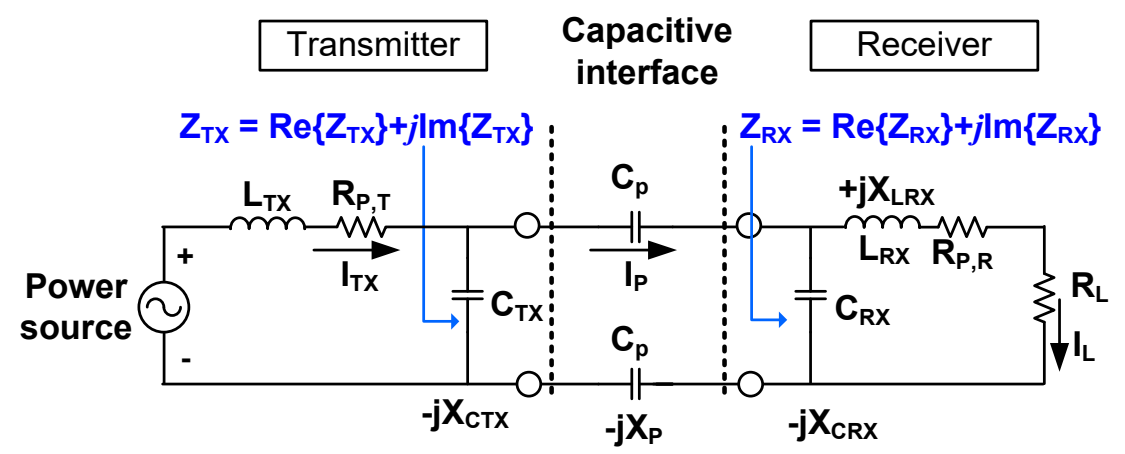

Figure 1. Equivalent circuit of a capacitive wireless-power transfer system. $\operatorname{The} \operatorname{Re}\left\{Z_{T X}\right\}$ resistance at the transmitter should be high compared to $R_{P, T}$ in order to achieve high Tx-to-Rx efficiency.

Reference [11] proposed that the matching capacitor should be small in order to reduce sensitivity to parameter variations and voltage stress. Through this method, the drift of system performance against load or component variation would be minimized.

While the various design methods mentioned above aimed to achieve different goals, such as constant output, wide bandwidth, high power factor, or reduced sensitivity, none of them explicitly defined the optimum $R X$ capacitance for maximum efficiency. This paper investigates exactly what optimum capacitance value could maximize the transfer efficiency for a given set of system parameters, such as coupling plates, load, and matching inductors. The results showed that the optimum $R X$ capacitor value should be smaller than that of a value that achieves complete LC resonance. A quantitative closed-form equation predicted the optimum capacitor value as a function of coupling plates, load, and inductors.

\section{Optimum Resonant Matching Capacitor}

\subsection{Circuit Topology of Capacitive Power System}

Figure 1 shows the equivalent circuit of capacitive power transfer. This work used a differential Class-E amplifier that produced a sinusoid output voltage and current. Its schematic and measured waveform is presented in Figure 8. However, this mathematical derivation was also applicable to a square-wave voltage source as well (e.g., voltage-mode Class-D inverter) because the first-harmonic approximation was valid due to the high-Q of the matching network. In other words, due to the high selectivity of $L_{T X}-C_{T X}$ resonance, higher frequency components of $I_{T X}$ were suppressed and $I_{T X}$ became sinusoidal. Since the impedance of capacitive interface, $X_{P}=\left(\omega C_{P} / 2\right)^{-1}$, is extremely high in noncontact applications, it is common to boost the receiver load $R_{L}$ using an $L_{R X}-C_{R X}$ network. The parallel resonance of $L_{R X}-C_{R X}-R_{L}$ increases the real part of $Z_{R X}$ while minimizing the reactance of $Z_{R X}$.

For the given $L_{R X}$ inductance, the $C_{R X}$ capacitance would normally be chosen such that $L_{R X}-C_{R X}$ was resonant at the operating frequency. This was to maximize the real part of $Z_{R X}$ (i.e., $\operatorname{Re}\left\{Z_{R X}\right\}$ ) while minimizing the reactive part of $Z_{R X}\left(\operatorname{Im}\left\{Z_{R X}\right\}\right)$. In this paper, however, we revealed that an exact $L C$ resonance was not the optimum design for efficiency maximization. Rather, the capacitance should be slightly smaller, such that there exists significant inductive impedance in $Z_{R X}$. $\operatorname{This} \operatorname{Im}\left\{Z_{R X}\right\}$ partially cancels out the larger capacitive $X_{P}$. Although the $\operatorname{Re}\left\{Z_{R X}\right\}$ obtained via the proposed shifted resonance was lower than that obtained with exact $L C$ resonance, it is also analyzed in this paper that a higher $\operatorname{Re}\left\{Z_{R X}\right\}$ is not always beneficial: there was an optimum $\operatorname{Re}\left\{Z_{R X}\right\}$. 


\subsection{Analytical Derivation for Optimum $\mathrm{C}_{\mathrm{RX}}$}

The Tx-to-Rx efficiency of Figure 1 was defined as

$$
\begin{aligned}
\eta_{T X-t o-R X} & =\frac{\text { Load power }}{\text { Supplied power by source }} \\
& =\frac{I_{L}^{2} R_{L}}{I_{T X}^{2}\left(\operatorname{Re}\left\{Z_{T X}\right\}+R_{P, T}\right)}
\end{aligned}
$$

The $Z_{T X}$ is the equivalent impedance with regard to the $C_{T X}$ capacitance, and $R_{P, T}$ and $R_{P, R}$ are the parasitic resistance of the $L_{T X}$ and $L_{R X}$ inductors, respectively. Equation (1) can be separated into a two-stage equation. The first stage, which was the transmitter efficiency, consisted of the power entering the capacitive interface $I_{T X}^{2} \operatorname{Re}\left\{Z_{T X}\right\}$, divided by the total power supplied from our power source $I_{T X}^{2}\left(\operatorname{Re}\left\{Z_{T X}\right\}+R_{P, T}\right)$. The second stage, which was the receiver efficiency, consisted of the power dissipation at final load divided by the power dissipation across the whole receiver. Hence, Equation (1) could be written as

$$
\eta_{T X-t o-R X}=\frac{I_{T X}^{2} \operatorname{Re}\left\{Z_{T X}\right\}}{I_{T X}^{2}\left(\operatorname{Re}\left\{Z_{T X}\right\}+R_{P, T}\right)} \times \frac{I_{L}^{2} R_{L}}{I_{L}^{2}\left(R_{L}+R_{P, R}\right)}
$$

thereby arriving at the impedance ratio equation of

$$
\eta_{T X-t o-R X}=\frac{\operatorname{Re}\left\{Z_{T X}\right\}}{\operatorname{Re}\left\{Z_{T X}\right\}+R_{P, T}} \times \frac{R_{L}}{R_{L}+R_{P, R}}
$$

Since the power delivered to the receiver was equal to the power dissipated at the $\operatorname{Re}\left\{Z_{T X}\right\}$, it was important that we obtained a large value of $\operatorname{Re}\left\{Z_{T X}\right\}$ to maximize transmission efficiency. In other words, the power delivered to $R X$ is $P=\left|I_{T X}\right|^{2} \operatorname{Re}\left\{Z_{T X}\right\}$, whereas the power dissipated at $T X$ parasitic is $P=\left|I_{T X}\right|^{2} R_{P, T}$. Hence, the $\operatorname{Re}\left\{Z_{T X}\right\}$ should have been higher than $R_{P, T}$. The $\operatorname{Re}\left\{Z_{T X}\right\}$ is defined found as follows:

$$
\operatorname{Re}\left\{Z_{T X}\right\}=\frac{X_{C T X}^{2} \operatorname{Re}\left\{Z_{R X}\right\}}{\operatorname{Re}\left\{Z_{R X}\right\}^{2}+\left(X_{C T X}+X_{P}-\operatorname{Im}\left\{Z_{R X}\right\}\right)^{2}}
$$

where $\operatorname{Re}\left\{Z_{R X}\right\}$ and $\operatorname{Im}\left\{Z_{R X}\right\}$ is

$$
\begin{gathered}
\operatorname{Re}\left\{Z_{R X}\right\}=\frac{X_{C R X}^{2} R_{L}}{R_{L}^{2}+\left(X_{L R X}-X_{C R X}\right)^{2}} \\
\operatorname{Im}\left\{Z_{R X}\right\}=-\frac{X_{C R X}\left\{X_{L R X}\left(X_{L R X}-X_{C R X}\right)+R_{L}^{2}\right\}}{R_{L}^{2}+\left(X_{L R X}-X_{C R X}\right)^{2}}
\end{gathered}
$$

and $X_{C T X}=\left(\omega C_{T X}\right)^{-1}, X_{C R X}=\left(\omega C_{R X}\right)^{-1}, X_{P}=\left(\omega C_{P} / 2\right)^{-1}$, and $X_{L R X}=\omega L_{R X}$.

After substituting Equations (5) and (6) into Equation (4), Equation (4) became a function of the receiver parameters, such as $R_{L}, X_{L R X}$, and $X_{C R X}$. The typical complete resonance, $\omega=1 / \sqrt{L_{R X} C_{R X}}$, almost cancelled out the $\operatorname{Im}\left\{Z_{R X}\right\}$, whereas the opposite was true for the $\operatorname{Re}\left\{Z_{R X}\right\}$, which was maximized.

In this paper, we tested the theory that there may be an optimum $C_{R X, o p t}$ to maximize the efficiency of Equation (3) for any given set of system parameters. Our efficiency maximization was realized by a maximum $\operatorname{Re}\left\{Z_{T X}\right\}$ resistance and a corresponding minimum $I_{T X}$ current, thereby suppressing power losses at the inverter and TX passive components thanks to a minimum of $I_{T X}$ current.

Differentiating Equation (4) with respect to $X_{C R X}$ and setting this differentiation to zero, i.e., $\partial \operatorname{Re}\left\{Z_{T X}\right\} / \partial X_{C R T}=0$, the optimum $X_{C R X}$ was derived: 


$$
X_{C R T, o p t}=\frac{\left(\left(R_{L}+R_{P, R}\right)^{2}+X_{L R X}^{2}\right)\left(X_{P}+X_{C T X}\right)}{X_{L R X}\left(X_{P}+X_{C T X}\right)-\left(R_{L}+R_{P, R}\right)^{2}-X_{L R X}^{2}}
$$

Note that the derivation of Equation (7) does not involve any approximations and therefore was generally applicable for any given set of system parameters e.g., load, $L_{R X}, C_{P}, C_{T X}$ etc. Equation (7) can be simplified because the coupling plate impedance, $X_{P}$, is usually a much higher value than the $X_{\text {CTX }}$ [2,3]. Moreover, the Rx inductor reactance, $X_{L R X}$, is also usually designed as a much higher value than $R_{L}$ in order to boost a small $R_{L}$ into a large $\operatorname{Re}\left\{Z_{R X}\right\}$, generally because $\operatorname{Re}\left\{Z_{R X}\right\} \approx X_{L R X}^{2} / R_{L}$. Under these conditions, Equation (7) was simplified as follows:

$$
X_{C R X, o p t} \cong X_{L R X}\left(1-\frac{X_{L R X}}{X_{P}}\right)^{-1}
$$

Equation (8) indicated that the optimum $X_{C R X}$ impedance, which maximized the $\operatorname{Re}\left\{Z_{T X}\right\}$ and our efficiency, should be higher than the inductor impedance $X_{L R X}$. The ratio between inductor impedance and coupling plate impedance, i.e. $X_{L R X} / X_{P}$, determined the level of deviation from the complete LC canceling condition of $X_{C R X}=X_{L R X}$. Equation (8) indicated that a higher ratio of $X_{L R X} / X_{P}$ required a larger deviation of $X_{C R X}$ from the $X_{L R X}$.

\subsection{Discussion}

Figure $2 \mathrm{~b}$ is the $Z_{R X}$ representation of Figure $2 \mathrm{a}$ at a conventional resonance. Conventional $R X$ cancelled the $\operatorname{Im}\left\{Z_{R X}\right\}$ while maximizing the $R_{L}$ into a high $\operatorname{Re}\left\{Z_{R X}\right\}$ so that the power factor of $Z_{C A P}$ was maximized. However, higher $\operatorname{Re}\left\{Z_{R X}\right\}$ was not always beneficial for $T X$-to- $R X$ efficiency. As seen in Figure 1, the $I_{T X}$ supplied from the inverter was directed toward two separate paths: one was through $C_{T X}$ (which did not contribute to power delivery), and the other was through $I_{P}$ flowing into the receiver. If $\operatorname{Re}\left\{Z_{R X}\right\}$ was too high, then most of the $I_{T X}$ was circulated to $C_{T X}$ and only limited current could flow through $I_{P}$, which resulted in a reduced power efficiency. The bottom graph of Figure $2 \mathrm{~d}$ shows that at conventional resonance the $I_{T X}$ required to deliver a specified $I_{L}$ should have been increased.

However, the proposed $C_{R X}$ detuning in Figure 2c did not maximize the $\operatorname{Re}\left\{Z_{R X}\right\}$ and, at the same time, intentionally generated $+\operatorname{Im}\left\{Z_{R X}\right\}$. This partially cancelled $X_{P}$ by detuning $L_{R X}-C_{R X}$. Its impedance, as seen in Figure 2d, was a frequency of 7.1 MHz. The overall impedance $\left|Z_{C A P}\right|=\operatorname{Re}\left\{Z_{R X}\right\}$ $+j\left(\operatorname{Im}\left\{Z_{R X}\right\}-X_{P}\right)$ was significantly reduced compared to conventional $L_{R X}-C_{R X}$. As a result, the bottom graph of Figure $2 \mathrm{~d}$ shows that the $I_{T X}$ current required to deliver a given load current $I_{L}$ could be minimized, which in turn could reduce the losses in the transmitter.

The exact amount of detuning of $L_{R X}-C_{R X}$ was quantitatively obtained from Equations (7) and (8). Figure 3 illustrates the design trade-off. In Figure $3 a$, while $\operatorname{Re}\left\{Z_{R X}\right\}$ should have been high to maximize the load power per unit $I_{P}$ of current, the $\operatorname{Re}\left\{Z_{R X}\right\}$ should not have been so excessively high that the $I_{P}$ current per unit $I_{T X}$ could not be maintained. At the same time, in Figure $3 \mathrm{~b}, j \operatorname{Im}\left\{Z_{R X}\right\}-j X_{P}$ was minimized by maximizing the $+j \operatorname{Im}\left\{Z_{R X}\right\}$ so that the $I_{P}$ was increased per given $I_{T X}$. However, as seen in Figure $3 c$, excessively high $\operatorname{Im}\left\{Z_{R X}\right\}$ may have compromised the achievable $\operatorname{Re}\left\{Z_{R X}\right\}$. The proposed Equations (7) and (8) optimized the trade-offs of Figure 3 and produced an optimum $\operatorname{Re}\left\{Z_{R X}\right\}$ and $\operatorname{Im}\left\{Z_{R X}\right\}$ that maximized power efficiency. 


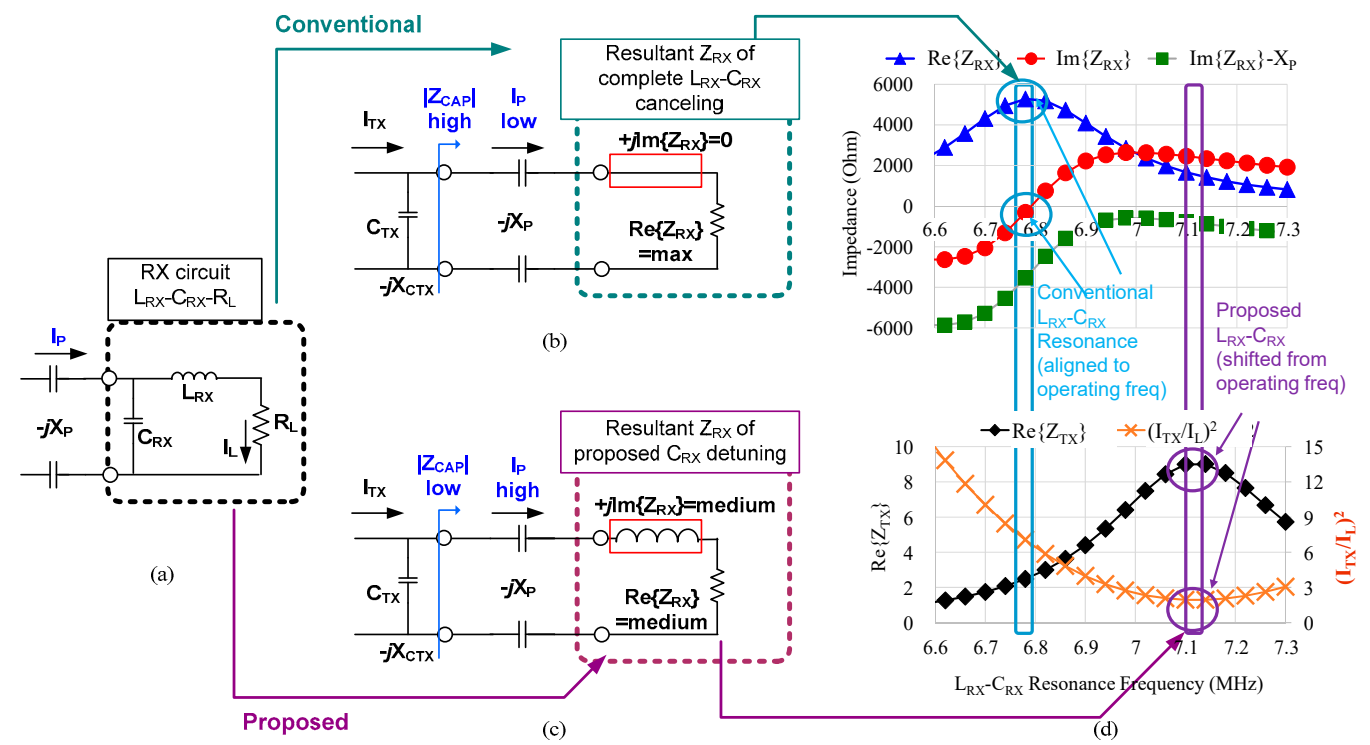

Figure 2. Comparison between conventional resonance and proposed $C_{R X}$. (a) $R X$ circuit consisting of $L_{R X}-C_{R X}$ and load $R_{L}$. (b) Typical complete LC canceling causes high $Z_{C A P}$ and low $I_{P}$. (c) Proposed $C_{R X}$ condition yields a high $+j \operatorname{Im}\left\{Z_{R X}\right\}$ that partially cancels the high $-j X_{P}$ of the coupling plates. Moreover, $\operatorname{Re}\left\{Z_{R X}\right\}$ was moderate. The two improvements of $Z_{R X}$ allowed a higher $I_{P}$ current toward $R X$. (d) The $x$-axis was $L_{R X}-C_{R X}$ resonance frequency. Operating frequency was fixed at $6.78 \mathrm{MHz}$. The proposed $C_{R X}$ of Equation (7) partly cancels the $-j X_{P}$ impedance and yields an appropriate value of $\operatorname{Re}\left\{Z_{R X}\right\}$, both of which increased the current $I_{P}$ and maximized the load power. This maximized $\operatorname{Re}\left\{Z_{T X}\right\}$ and minimized the $I_{T X}$ required to deliver a given load current $I_{L}$. $C_{T X}=168.5 \mathrm{pF}, C_{P}=14.5 \mathrm{pF}$.

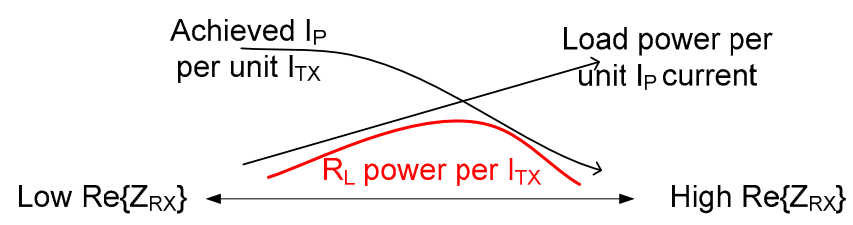

(a), for given $\operatorname{Im}\left\{Z_{\mathrm{R} x}\right\}$
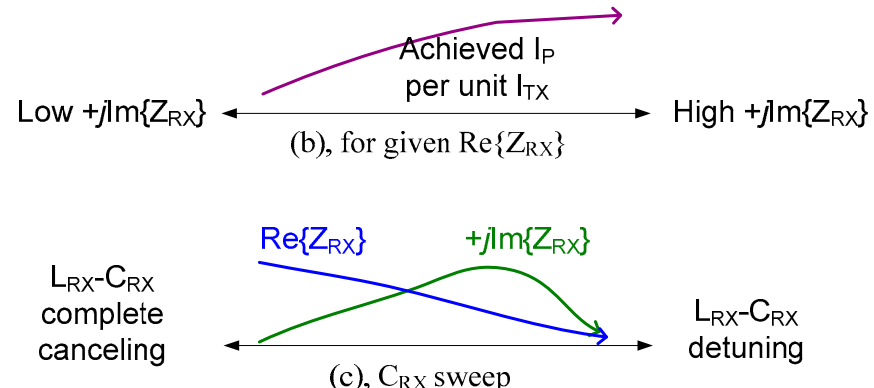

Figure 3. Design considerations. Equation (7) optimized $C_{R X}$ tuning, when considering all the trade-offs. (a) $\operatorname{Re}\left\{Z_{R X}\right\}$ optimization to maximize $R_{L}$ power per given $I_{T X}$. (b) High $+\mathrm{j} \operatorname{Im}\left\{Z_{R X}\right\}$ improved the $I_{P}$ per given $I_{T X}$. However, (c) excessively high $\operatorname{Im}\left\{Z_{R X}\right\}$ compromised the achievable $\operatorname{Re}\left\{Z_{R X}\right\}$.

Figure 4 compares the conventional and the proposed methods. The proposed method surpassed the upper limit imposed by conventional $R X$ tuning. 


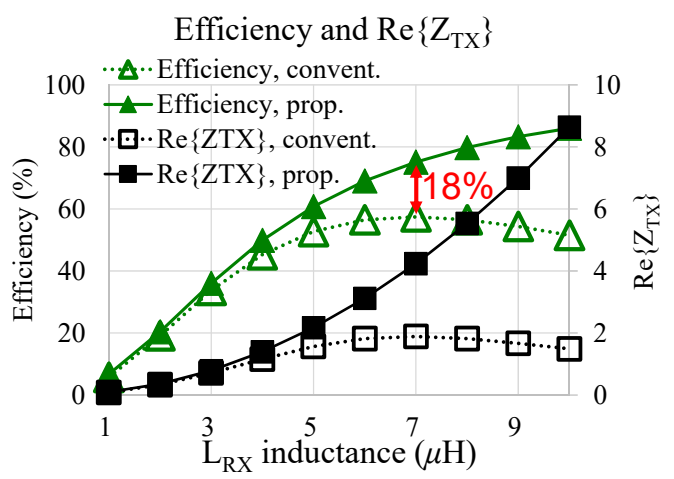

Figure 4. Calculated efficiency and $\operatorname{Re}\left\{Z_{T X}\right\}$. The proposed method always achieves higher efficiency than conventional tuning method for every value of $L_{R X}$.

The high $\operatorname{Re}\left\{Z_{T X}\right\}$ might also be obtained by using a small $C_{T X}$, as in Equation (4). However, a small $C_{T X}$ demands a large $L_{T X}$, which increases inductor volume and parasitic $R_{P, T}$. As an example, in Figure $2 \mathrm{~d}$ the bottom graph typical resonance still gives the same $\operatorname{Re}\left\{Z_{T X}\right\}=9 \Omega$ if the $C_{T X}$ was reduced from 168.5 to $87.5 \mathrm{pF}$. However, then the required $L_{T X}$ should have increased from 3.8-6.8 $\mu \mathrm{H}$. Due to the increased parasitic $R_{P, T}$, the spice-simulated efficiency degraded from $77.4 \%$ to $69.9 \%$. Hence, an optimum $C_{R X, \text { opt }}$ becomes important in order to produce the highest $\operatorname{Re}\left\{Z_{T X}\right\}$ under the constraint of $L_{T X}$ volume and parasitic resistance.

\section{Results}

Figure 5 shows the measurement setup using wireless charging of an unmanned aerial vehicle (Drone) prototype can be seen in Figure 5. The load condition was $36 \mathrm{~V}-1.8 \mathrm{~A}$ and resulted in a value of $64.8 \mathrm{~W}$. A differential Class-E inverter and full-bridge rectifier were used. Efficiency in this paper was defined as from DC source to DC load.

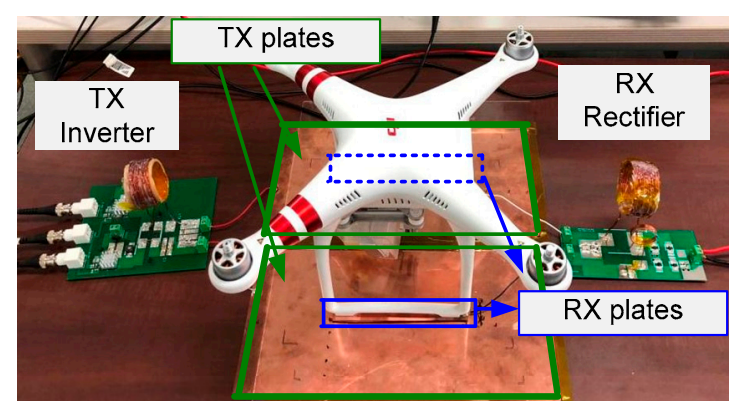

Figure 5. Measurement validation using the unmanned aerial vehicle prototype. The TX plates were protected by a $2-4 \mathrm{~mm}$ thick acrylic sheet to prevent hazardous electrical shorts caused by collision with unexpected foreign objects.

A $0.2 \mathrm{~mm}$ thick copper plate was used for each plate. A transmit plate of $30 \times 30 \mathrm{~cm}^{2}$ was placed underneath the landing pad and a receiver plate of $13 \times 1.5 \mathrm{~cm}^{2}$ was attached under the landing foot of the UAV. The $C_{P}$ was 23 and $14 \mathrm{pF}$ for a 2 and $4 \mathrm{~mm}$ distance, respectively. These distances were due to electrical isolation by way of an acrylic sheet to prevent electrical shorts and mechanical damage of the $T X$ plates that may have resulted from a collision with foreign objects. $L_{T X}, L_{R X}$, and $C_{T X}$ were $3.8 \mu \mathrm{H}$, $7.13 \mu \mathrm{H}$, and $165 \mathrm{pF}$, respectively. A GS66508T FET and PMEG6045 diode were used as our inverter and rectifier, respectively. Please note that Equations (7) and (8) are generally applicable to different systems with different component parameters. Table 1 provides circuit parameters. 
Table 1. Circuit parameters.

\begin{tabular}{cccc}
\hline Parameter & Value & Parameter & Value \\
\hline $\mathrm{C}_{\mathrm{p}}$ & $14 \sim 23 \mathrm{pF}$ & Load & $36 \mathrm{~V}, 64.8 \mathrm{~W}$ \\
$\mathrm{~L}_{\mathrm{TX}}$ & $3.8 \mu \mathrm{H}$ & TX plate & $30 \times 30 \mathrm{~cm}^{2}$ \\
$\mathrm{~L}_{\mathrm{RX}}$ & $7.13 \mu \mathrm{H}$ & RX pad & $13 \times 1.5 \mathrm{~cm}^{2}$ \\
$\mathrm{C}_{\mathrm{TX}}$ & $165 \mathrm{pF}$ & Switching freq. & $6.78 \mathrm{MHz}$ \\
\hline
\end{tabular}

Figure 6a presents the DC-to-DC efficiency for each $R X$ capacitor value. A $L_{R X}$ value of $7.13 \mu \mathrm{H}$ was chosen because, as can be seen from Figure 4, efficiency could be maximized near $\sim 7 \mu \mathrm{H}$ at a Cp of $10 \mathrm{pF}$ (worst coupling) using typical LC resonance. The $C_{R X}$ of $77.3 \mathrm{pF}$ corresponded to typical LC resonance, whose resonance frequency coincided with an operating frequency of $6.78 \mathrm{MHz}$. The optimum $C_{R X, o p t}$ was predicted by Equation (8) for different $C_{P}$ coupling plates. As expected, our proposed $C_{R X, o p t}$ values achieved the highest efficiency for the given set of system constraints. Figure $6 \mathrm{~b}$ presents the $I_{T X}$ current required to deliver the given load power, which was minimized at the proposed $C_{R X, o p t}$ capacitor tuning. This result was expected because Equations (7) and (8) maximized the $\operatorname{Re}\left\{Z_{T X}\right\}$, and therefore the power delivered to the receiver, which was $P=\left|I_{T X}\right|^{2} \operatorname{Re}\left\{Z_{T X}\right\}$.

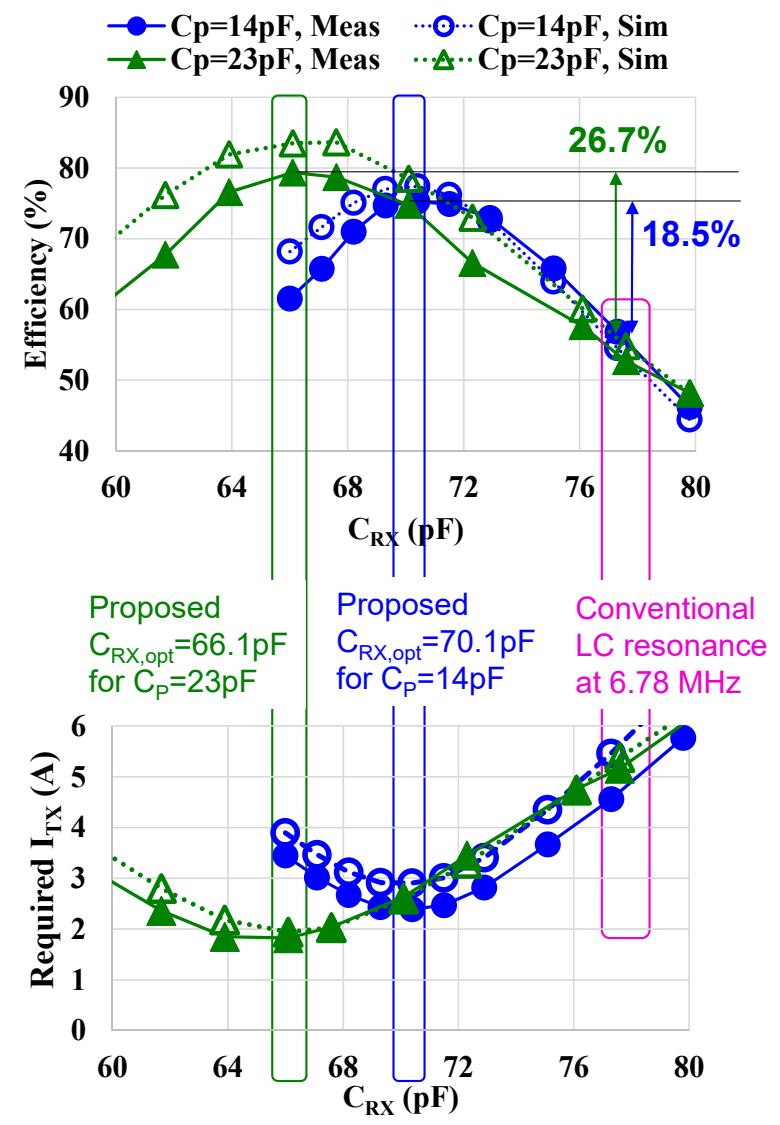

Figure 6. Proposed tuning that achieved higher efficiency. (a) Efficiency vs. $C_{R X}$ for $L_{R X}=7.13 \mu \mathrm{H}$. The proposed $C_{R X}$ values achieved higher efficiency than the conventional exact LC resonance. (b) $I_{T X}$ current required to deliver a given load power. The proposed $C_{R X}$ condition lowered the required $I_{T X}$ current, thereby reducing the power loss of the transmitter.

Figure 7 presents the loss analysis for the same load power. The proposed $C_{R X, o p t}$ greatly reduced the power loss of the transmitter. This was because the $C_{R X}$ affected the $\operatorname{Re}\left\{Z_{T X}\right\}$, which in turn determined the magnitude of current through the transmitter. The waveform in Figure 8 shows that the inverter achieved zero-voltage switching. 


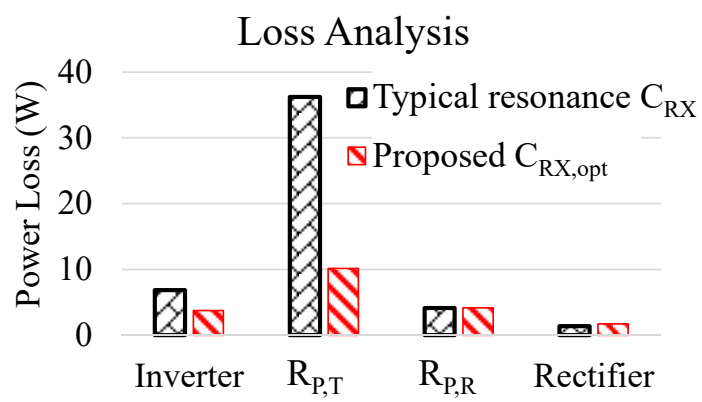

Figure 7. Loss breakdown analysis for the same load power. The proposed method improved the losses in transmission while not affecting the receiver-loss characteristics.

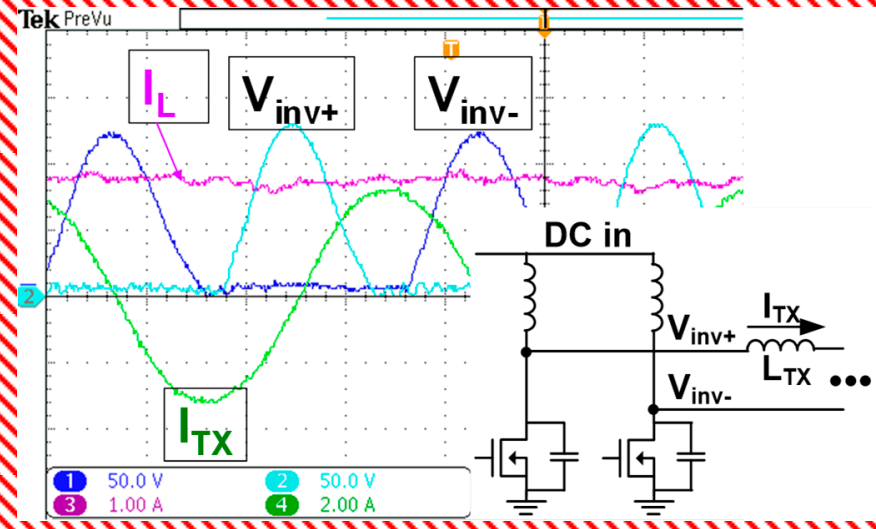

Figure 8. Measured waveforms. The inverter was operated at $6.78 \mathrm{MHz}$ using zero-voltage switching.

\section{Conclusions}

This paper thoroughly reveals the optimum parallel capacitance value of a receiver for a given set of system parameters. Our finding showed that a complete LC resonance at operating frequency did not result in the highest efficiency. Rather, the $R X$ capacitor should have been be of a smaller capacitance value than the nominal resonance-tuning value. The optimal deviation from nominal resonance should have been proportional to the ratio between the $R X$ inductor impedance and the coupling plate impedance, as formulated in Equation (8). This minimized our $I_{T X}$ value and its associated losses in the transmitter, thereby increasing overall efficiency while not affecting receiver loss characteristics.

Author Contributions: Conceptualization, S.H. and D.A.; Formal analysis, S.H. and D.A.; Funding acquisition, D.A.; Methodology, S.H. and D.A.; Project administration, D.A.; Supervision, D.A.; Validation, S.H.

Funding: This work is supported by Incheon National University Grant (\#2018-0156).

Conflicts of Interest: The authors declare no conflict of interest.

\section{References}

1. Jegadeesan, R.; Agarwal, K.; Guo, Y.-X.; Yen, S.-C.; Thakor, N.V. Wireless power delivery to flexible subcutaneous implants using capacitive coupling. IEEE Trans. Microwave Theory Tech. 2017, 65, $280-292$. [CrossRef]

2. Regensburger, B.; Kumar, A.; Sinha, S.; Doubleday, K.; Pervaiz, S.; Popovic, Z.; Afridi, K. High-Performance Large Air-Gap Capacitive Wireless Power Transfer System for Electric Vehicle Charging. In Proceedings of the 2017 IEEE Transportation Electrification Conference and Expo (ITEC), Chicago, IL, USA, 26-28 June 2017; pp. 638-643. 
3. Lu, F.; Zhang, H.; Hofmann, H.; Mi, C. A double-sided LC compensation circuit for loosely-coupled capacitive power transfer. IEEE Trans. Power Electron. 2018, 33, 1633-1643. [CrossRef]

4. Zhang, H.; Lu, F.; Hofmann, H.; Liu, W.; Mi, C. A four-plate compact capacitive coupler design and LCL-compensated topology for capacitive power transfer in electric vehicle charging application. IEEE Trans. Power Electron. 2016, 31, 8541-8551.

5. Zhang, H.; Lu, F.; Hofmann, H.; Liu, W.; Mi, C. Six-plate capacitive coupler to reduce electric field emission in large air gap capacitive power transfer. IEEE Trans. Power Electron. 2017, 33, 665-675. [CrossRef]

6. Dai, J.; Ludois, D. Biologically Inspired Coupling Pixilation for Position Independence in Capacitive Power Transfer Surfaces. In Proceedings of the 2015 IEEE Applied Power Electronics Conference and Exposition (APEC), Charlotte, NC, USA, 15-19 March 2015.

7. Su, Y.-G.; Xie, S.-Y.; Hu, A.; Tang, C.-S.; Zhou, W.; Huang, L. A capacitive power transfer system with a mixed-resonant topology for constant-current multiple-pickup applications. IEEE Trans. Power Electron. 2017, 32, 8778-8786. [CrossRef]

8. Theodoridis, M. Effective capacitive power transfer. IEEE Trans. Power Electron. 2012, 27, 4906-4913. [CrossRef]

9. Zhang, H.; Lu, F. An improved design methodology of the double-sided LC-compensated CPT system considering the inductance detuning. IEEE Trans. Power Electron. 2019, 34, 11396-11406. [CrossRef]

10. Li, S.; Liu, Z.; Zhao, H.; Zhu, L.; Shuai, C.; Chen, Z. Wireless power transfer by electric field resonance and its application in dynamic charging. IEEE Trans. Ind. Electron. 2016, 63, 6602-6612. [CrossRef]

11. Mostafa, T.; Bui, D.; Muharam, A.; Hattori, R.; Hu, A. A Capacitive Power Transfer System with a CL Network for Improved System Performance. In Proceedings of the 2018 IEEE Wireless Power Transfer Conference (WPTC), Montreal, QC, Canada, 3-7 June 2018.

(C) 2019 by the authors. Licensee MDPI, Basel, Switzerland. This article is an open access article distributed under the terms and conditions of the Creative Commons Attribution (CC BY) license (http://creativecommons.org/licenses/by/4.0/). 